\title{
Emotional Intelligence and Work Performance
}

\author{
Jasleen Kaur, Anupam Sharma
}

\begin{abstract}
Performance of organization employees is very much affected by various work place factors. To complete the assignment within the defined time frame, performance is one of the key skill necessitated. There are numerous of aspects that have impact on the work performance of employees. The main theme of this research revolves around studying factors affecting work performance of employees and to study the influence of emotional intelligence on work performance of employees.
\end{abstract}

Keywords: Performance, organization, employees, emotional intelligence.

\section{INTRODUCTION}

Emotions have a substantial impact upon the intelligence of an individual and organization work culture has been very much effected by the same. As stated by Ashkanasy and Daus (2005); Giardini and Frese (2006), the concept of Emotional Intelligence (EI) has gained popularity yet remained an ignorant topic. As cited by Kafetsios and Zampetakis (2008), EI plays a significant role in emerging perspective of 'affective revolution' in social and organizational psychology.

Goleman (1995, 1998); Salovey and Mayer (1990), defined EI as an ability to recognise one's emotions and regulate them accordingly. Many researchers have tried to find the nature of relationship that exists between EI and work performance. Lam and Kirby (2002); Semadar, et al., (2006) revealed that employee's performance can be best predicted by EI as it can project their productivity by understanding and managing their emotions in the preferred manner accordingly. According to researchers, EI empowers an individual to motivate oneself, boost persistence level, control impulses, regulate one's moods and thus, manage one's ability to think, to empathise and to hope. Further, Kierstead (1999); Bhalla and Nauriyal (2004), suggested that an emotionally intelligent person is proficient in two key areas namely, "personal competence" - ability of one to manage self; and "social competence" ability of one to manage relationships.

Revised Manuscript Received on July 22, 2019.

Jasleen Kaur, Anupam Sharma

\section{OBJECTIVES}

(1) To study the factors affecting Emotional intelligence

(2) To study the factors affecting work performance

(3) To study the impact of Emotional intelligence on work performance

\section{LITERATURE REVIEW}

\section{Emotional Intelligence}

According to Perlovsky (2006); Akgun et al., (2007) emotions are considered as one of the firm competencies apart from knowledge, dexterity, beliefs and routines used for demonstrating both expressive communication and inner feelings of love, hate, desire, sadness and aversion. Further, Mayer and Salovey (1990, 1995); Cote and Miners (2006) added to the definition by linking emotions with intelligence of person. The concept of EI has its foundation from the time as early as late 1930s, when the concept of non-intellective intelligence came into light.

EI has its root in the concept of 'social intelligence' as identified by Thorndike (1920) and explained as an ability to comprehend, manage and act prudently in human relations. Goleman (1998, 2001); Bar-On (2000) elaborated the term EI as the ability to realise one's own feelings and then regulate them appropriately. They also stated that EI helps in understanding and managing emotions of others in order to accomplish organizational needs effectively. Further, Orme (2003), elaborated EI as the proficiency of understanding emotions of one-self and others and then, taking favourable actions accordingly. In today's uncertain and dynamic work environment, job satisfaction, leadership, employee performance and organizational commitment are associated with emotional health of employees. Therefore, according to Daus and Ashkanasy (2005), EI acts as main analyst for managing employees' emotions and social skills. This is possible through self-consciousness that inbuilt potential to perceive strengths, emotions, worth and capabilities. Mayer and Salovey (1997) defined EI as "ability to perceive, appraise, express, understand and regulate emotions." Further, Goleman (1998) proposed five key factors of EI at work which helped in evaluation of EI level of leaders given below:
Published By:

Blue Eyes Intelligence Engineering \& Sciences Publication 


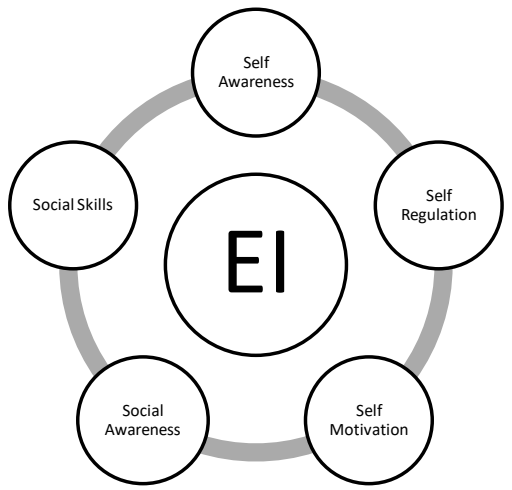

Figure 1: Five key factors of EI at work

\begin{tabular}{|l|l|l|l|}
\hline \multicolumn{2}{|l|}{ Table 1: Framework of EI } & Social competence \\
\hline Personal competence & $\begin{array}{l}\text { Social-awareness } \\
\text { Self-appraisal } \\
\text { Self-assurance }\end{array}$ & $\begin{array}{l}\text { Responsiveness } \\
\text { Improving others }\end{array}$ \\
\hline Self-awareness & $\begin{array}{l}\text { Loyalty } \\
\text { Positivity } \\
\text { Self- realization }\end{array}$ & Social skills & $\begin{array}{l}\text { Leadership } \\
\text { Communication } \\
\text { Managing conflicts } \\
\text { Building teams }\end{array}$ \\
\hline Self-regulation & $\begin{array}{l}\text { Constancy } \\
\text { Scrupulousness } \\
\text { Malleability } \\
\text { Self-control }\end{array}$ & & \\
& & & \\
\hline
\end{tabular}

Source: (Consortium for Research on Emotional intelligence (2004), cited in Adhia et al. (2010)

\section{Work Performance}

Work Performance (WP) plays an imperative role in the advancement and development of an organization. According to Korkaew and Suthinee (2012) organizational effectiveness and success can be attained through enhanced individual's WP. Campbell et al., (1998) ; Rotundo and Rotman (2002) acknowledged use of WP by educators, the government, businesses and society as one of the leading dependent variables as it depicts employee's behaviour that significantly contribute to accomplishment of organizational goals. Patterson (1997); Wright et al., (2005) in their work confirmed the effects of constructive HR practices on the WP. Tseng and Huang (2011) concluded WP to be the end-result in human resource studies. Further, revealed that employee's motivation can enhance their performance by deploying ways including capacity building, increasing responsibility level, initiating positive attitude and introducing incentives. Many researchers worked to determine parameters to ascertain level of employee's WP in an organization. Baytos and Kleiner (1995) recommended quality of work, punctuality, performance and end-productivity to be accurate parameters to measure WP. Gatewood and Field (1998) pointed out effective training, productivity and human resource judgement as other important aspects to measure. Robbins (2001) elucidated how job outcomes, actions, and personal traits acts as the main components to measure WP holistically.

\section{FRAMEWORK}

Many studies have been conducted to study relationship between EI and WP on job. In present epoch, Emotionally Intelligent employees master their interactions with customers (Murray, 1998), management and colleagues by effectively using antecedent and response focused emotions. Ashforth and Humphrey (1995) opined that an emotionally intelligent 
employee is considered as an emotionally competent, mature and sensitive person because he manages, directs and control his emotions and deals with team harmoniously.

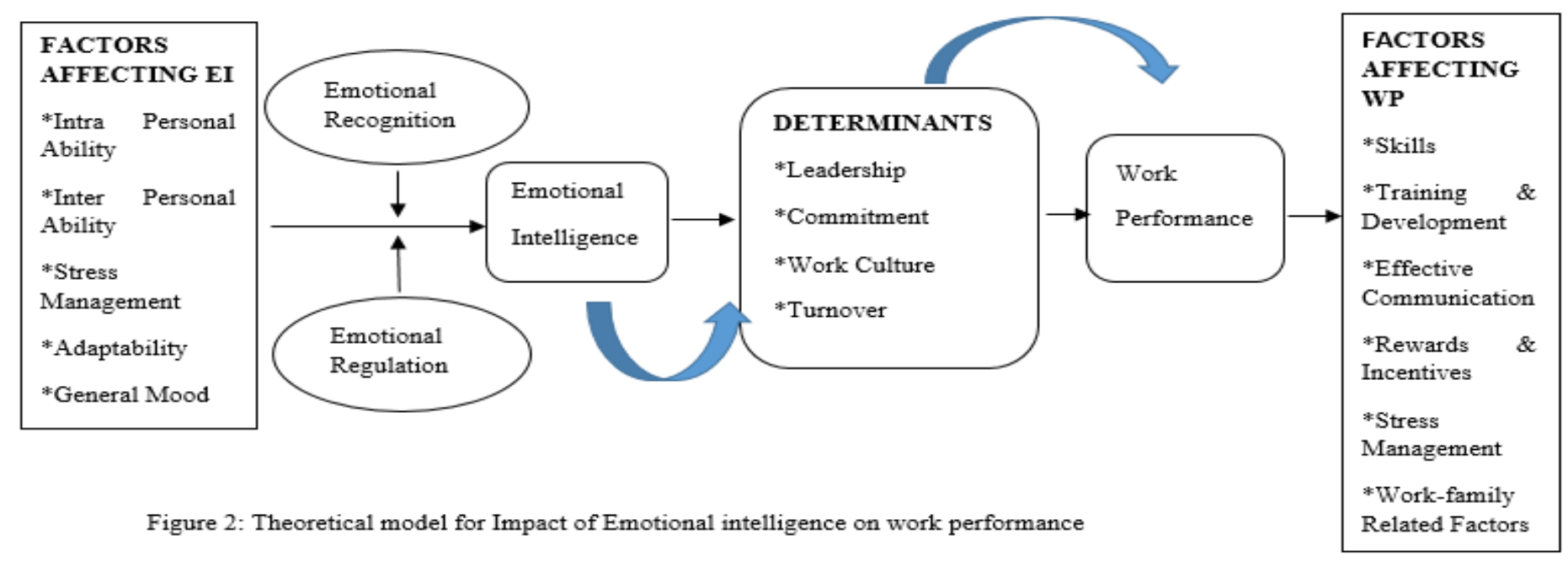

Figure 2: Theoretical model for Impact of Emotional intelligence on work performance

The above figure 2 explains the role of EI in enhancing work performance. EI augments leadership qualities and work commitment amongst employees so as to reduce employee's turnover and enrich work culture. Goleman et al., (2002); Bradberry and Greaves (2009) described that leaders exhibiting higher EI have potential to direct, reveal and influence overall EI of their followers and thus, positively impact organizational performance. EI is considered as key motivator for enhancing leadership qualities like adaptability, foresightedness, emotional stability and clear vision in the workforce making them capable of understanding emotions and regulating them accordingly. Also, according to Abraham (1999), EI helps in recognising the emotions of others, thus, nurturing leader with virtues of empathy, supportiveness, understanding and receptiveness towards team.

EI acts as a transforming agent that regulates and guides emotions of team, helps in managing conflicts to promote flexibility, acceptance to change and consequently a better work culture. Gardner (2003); Abraham (2000, 2003, 2004); Nikolaou and Tsaousis (2002) explored a constructive relationship between EI and organizational commitment. They concluded that workforce with high Emotional Quotient (EQ) consider themselves part and parcel of the organization, resulting in increased sense of fidelity and organizational commitment. Further, Nikolaou and Tsaousis (2002); Slaski and Cartwright (2003); Por et al., (2011); Karimi et al., (2014) revealed that emotionally intelligent people in an organization are considered to be more adaptive, diversified, unswerving and devoted because of their ability to control impulses, anxiety, burnout, well-being and emotions in adverse circumstances. This leads to reduced employee turnover and increased work performance. Thus, an emotionally competent employee accepts all complex tasks and is always eager to learn something new resulting to enhanced work performance and personal development.

\section{Factors Affecting Emotional Intelligence}

Salovey and Caruso (2000a) catalogued models of EI into two categories; namely ability model (Mayer and Salovey 1997) and mixed trait personality model (Goleman 1995, 1998; Bar-On 2001; Petrides and Furnham, 2001). Bestowing to ability models, Goldenberg et.al (2006) explained EI as the form of intelligence dealing with the emotional aspect and mental abilities of human being. In comparison, Matthews, Roberts and Zeidner (2004) explained mixed trait ability model to deal with personality-like traits along with emotional abilities. BarOn (2000) identified five factors including Intra personal Ability, Interpersonal ability, Stress Management, Adaptability and General mood affecting EI of an individual.

\section{Factors Affecting Work Performance}

According to Iqbal.A et al., (2015), Employee performance point out the "effectiveness of employee's explicit actions that aids to attain organizational goals". Alonso and Lewis (2001); Brewer and Selden (2000), found that many business organizations across the globe focusses on factors useful for enhancing 
employees' performance and provides incentives that can positively impact their job performance. Aarabi M.S et al, (2013) stated that companies provide various motivational factors to stimulate employees to achieve goals. Iqbal.A et al, (2015) described factors like working hours, training and development, effective communication, stress management and financial rewards to impact significantly on the work performance of employees. Further studies highlighted various factors including skills, enthusiasm, satisfaction, incentives and rewards crucial for job performance of employee.

\section{Impact of EI on Work Performance}

Most of the interpersonal interactions are administered by organizational performance relating to dealing customers, obtaining instructions and reporting to superiors and maintaining relationship with peers in an organization. EI acts as a key driver for regulating, directing and controlling emotional, personal and social competencies of people at work. EI has significant impact on the work performance. According to Ashforth and Humphrey (1995) team learning, effective team harmony and work culture is the result of effective use of EI. Murray (1998) emphasised on the role of EI in building inquisitive leaders to manage workforce by understanding emotions of employees in decision making. Further, he emphasised on the role of emotionally intelligent leaders in enhancing employee's morale thereby positively impacting on work performance.

The study by Kassim et al., (2016) conducted to examine the relationship between EI and job satisfaction amongst 2,502 university lecturer's within Kano state, using the Wong and Law scale and Convenience Sampling, revealed a significant relationship between emotional regulation and work satisfaction and no relationship of emotional appraisal with work performance. Similarly, the study steered by Vratskikh et al., (2016) using Mayer and Salvoy's (2000) ability model of EI explored the mediatory role of job satisfaction of 354 employees of Jordan University in relationship between EI and WP. The studies of Ashkanasy, Hooper (1999); Abraham (1999) along with Goleman (1998) proposed that higher EI led to higher job satisfaction, higher organizational commitment, more constructive emotional regulation and reduced employees turnover resulting to better work performance.

\section{Factors Contributing to Emotional Intelligence to Enhance Work Performance}

On the basis of literature reviewed, there are various factors that have contributed to EI and thereby, enhanced the WP of employees in service sector. These factors includes following -:
- Self-awareness - the ability to understand one's emotions, feelings, strengths, weaknesses and goals and their impact on others and decision making.

- Self-regulation - involves monitoring or redirecting one's unruly emotions and adjusting to adverse circumstances.

- Empathy - considering feelings of others in decision making.

- Motivation - stimulating actions for the sake of achievement of goal.

- Social awareness- the ability to apprehend other's emotions and guiding them effectively.

- Self-actualization- the ability to recognise one's prospective capacities.

- Flexibility - the ability to transform one's emotions and behaviour to modifying situations.

- Impulse Control - the ability to resist or slow down an impulse.

- Optimism- the positive ability to look at the brighter side of life.

- Conflict management: competency to handle, negotiate and resolve difficult situations tactfully.

- Team capabilities: competency to create synergy in team to ensure cooperation, spirit de corps and achieving organizational performance.

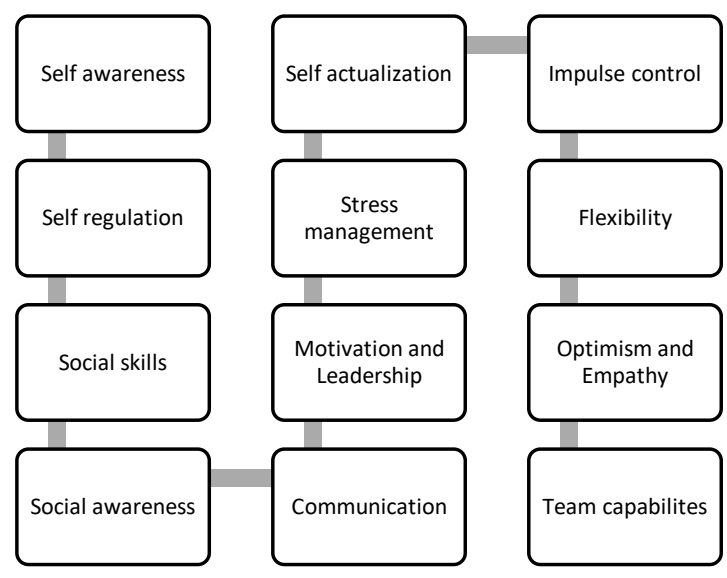

Figure3: Factors contributing to EI to enhance WP

\section{RESULT}

While the commercial world has started accepting Emotional Intelligence to be a 
forecaster for organizational success, the need is to strengthen the roots of organization with the water of emotionally aware individuals at workplace. Dierdoff \& Rubin (2011) in their study revealed that $68 \%$ of decision quality, $73 \%$ of coordination and $65 \%$ of conflict management is stimulated through high self-awareness. Also, OPRA group in their research with GENOS on EI empirically proved the need of EI in enhancing leadership traits by around $36 \%$, organizational commitment by $22 \%$, job satisfaction by $24 \%$ and reducing absenteeism by $29 \%$ in firm. The research advocated the need in need of emotionally intelligent workforce with $12 \%$ better innovative skills to provide $12 \%$ better customer services and $14 \%$ effective teamwork.

Average EQ Score by Industry

\begin{tabular}{|lc|}
\hline Industry & Average EQ Score \\
\hline Finance & 72 \\
High-tech & 72 \\
Government & 72 \\
Health Care & 73 \\
Pharmaceutical & 75 \\
Human Resources & 76 \\
\hline
\end{tabular}

Figure 4: Average Emotional Quotient score of different industries.
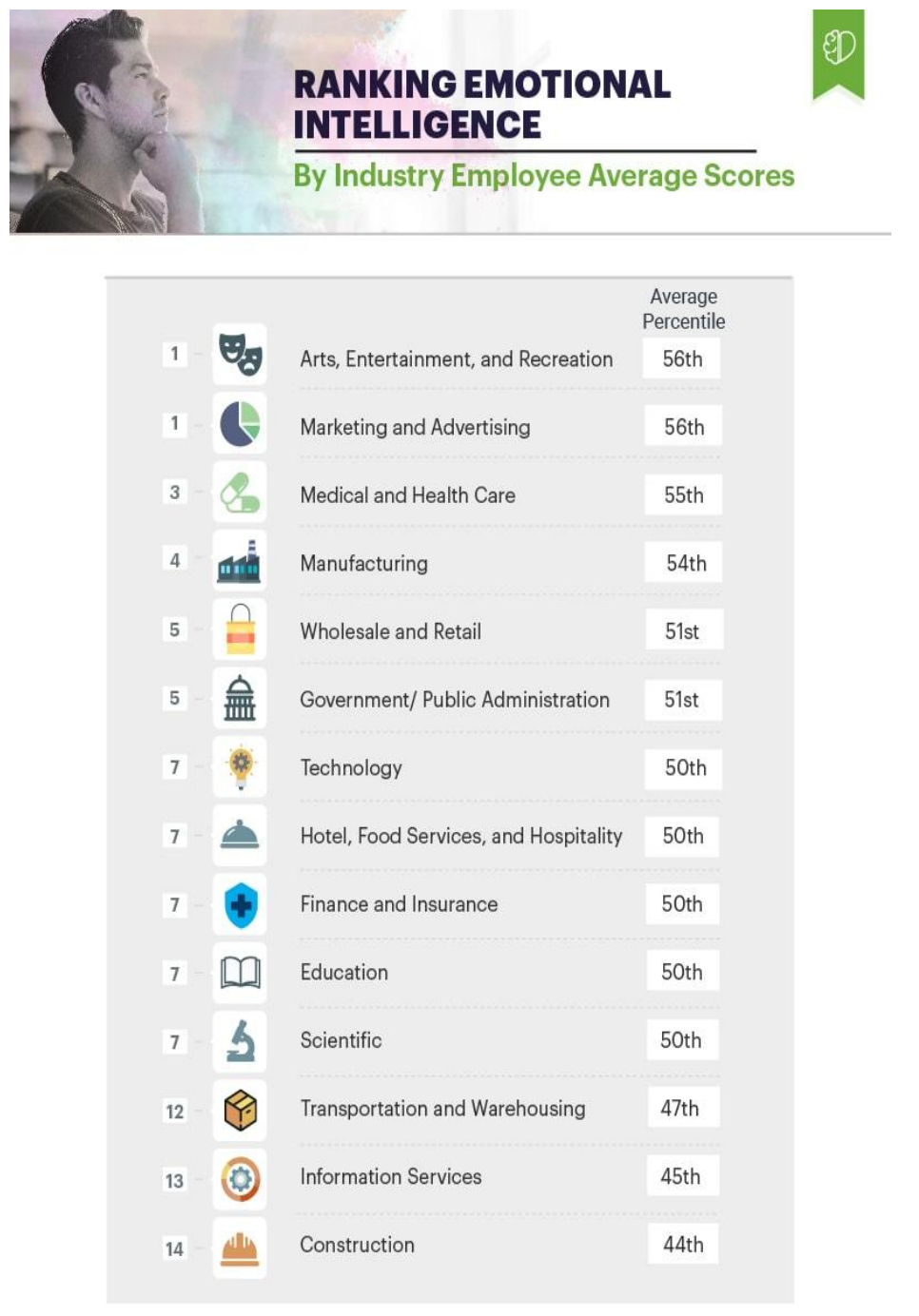

Source: Survey of 1,017 full-time employees

Figure 5: Average percentile EQ score by Industry employee average scores.

Previous research conducted in 200 companies worldwide indicated that around $2 / 3$ of the difference in work performance is due to emotional intelligence, and only $1 / 3$ due to technical skills and cognitive ability (Goleman, 1998). Also, in complicated jobs, a top performer is $127 \%$ more prolific than an average performer (Hunter, Schmidt \& Judiesch, 1990). 
Percentage Improvement of Emotional Intelligence

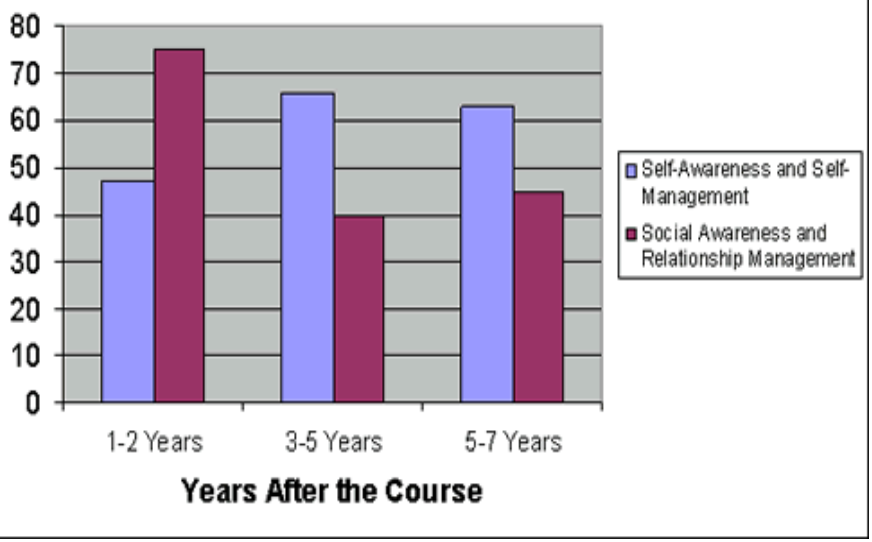

Figure 4: Percentage improvement of EI after the course

The training can help to enhance the level of selfawareness, self-management, social awareness and relationship management as shown in figure 4 above. Thus, the literature survey has resulted in showing the factors affecting work performance of employees and the influence of emotional intelligence on work performance of employees.

\section{CONCLUSION}

From the review of literature, it is observed that EI has a positive impact on work performance. Research by Lopes et al., (2006); Rahim (2010); Kumar and Rooprai (2009) confirmed EI to be an influential personality traits for working affectivity, enhancing job satisfaction and attaining organizational commitment. With improved commitment the turnover intention gets reduced significantly. Also, high EI results in team building by emotionally efficient leader, thus, refining work culture to successfully enhance work performance. Studies done so far as pointed out by Ashkanasy and Hooper (1999); Abraham (1999), a research by Goleman (1995), have suggested that high is the level of EI, higher will be job satisfaction, organizational commitment, job performance, and reduced turnover intention.

\section{VII.RESEARCH CONTRIBUTION}

Based on the literature reviewed, the paper focuses to build conceptual base and knowledge enhancement about the factors

https://www.forbes.com/sites/forbescoachescouncil/2018/0 3/22/how-and-why-to-develop-your-emotional-

intelligence/\#6d58025a669bimpacting

Emotional

Intelligence and Work performance. Also, the research work has developed a theoretical model that describes the role of EI on determinants including Leadership, Commitment, Work culture and Turnover on WP in an organization. The model if implemented in the business organizations will lower down the turnover rate by having more emotionally stable employees and balanced work culture will be impacting the overall growth of the organization.

\section{REFERENCES}

1. Allen, N. \& Meyer, J. (1990). The measurement and antecedents of affective, continuance, and normative commitment to the Organization. Journal of Occupational Psychology, 63: 1-18.

2. Baksh Baloch, Q., Saleem, M., Zaman, G., \& Fida, A. (2014). The Impact of Emotional Intelligence on Employees' Performance. Journal of Managerial Sciences, 8(2).

3. Boon, L. K., Fern, Y. S., Sze, C. C., \& Yean, O. K. (2012). Factors affecting individual job performance. In International Conference on Management, Economics and Finance.

4. Çekmecelioğlu, H. G., Günsel, A., \& Ulutaş, T. (2012). Effects of emotional intelligence on job satisfaction: An empirical study on call center employees. Procedia-Social and Behavioral Sciences, 58, 363-369.

5. Dulewicz, V., \& Higgs, M. (2003). Leadership at the top: The need for emotional intelligence in organizations. The International Journal of Organizational Analysis, 11(3), 193-210.

6. Goleman, D. (1995). Emotional intelligence. New York: Bantam Books.

7. Kassim, S. I., Bambale, A. J., \& Jakada, B. A. (2016). Emotional Intelligence and Job Satisfaction among Lecturers of Universities in Kano State: Empirical Evidence. Journal of Education and Practice, 7(10), 5359.

8. Naderi Anari, N. (2012). Teachers: emotional intelligence, job satisfaction, and organizational commitment. Journal of workplace Learning, 24(4), 256-269.

9. Narayan, P. R., Narashiman. Emotional intelligence and Work performance: A conceptual study. ISOR Journal of Mechanical and Civil Engineering, 62-68.

10. Rexhepi, G., \& Berisha, B. (2017). The effects of emotional intelligence in employee's performance. International Journal of Business and Globalisation, 18(4), 467-479.

11. Romanelli, F., Cain, J., \& Smith, K. M. (2006). Emotional intelligence as a predictor of academic and/or professional success. American journal of pharmaceutical education, 70(3), 69.

12. Salovey, P., \& Mayer, J. D. (1990). Emotional intelligence. Imagination, Cognition and Personality, 9 (3), $185-211$.

13. Vratskikh, I., Al-Lozi, M., \& Maqableh, M. (2016). The impact of emotional intelligence on job performance via the mediating role of job satisfaction. International Journal

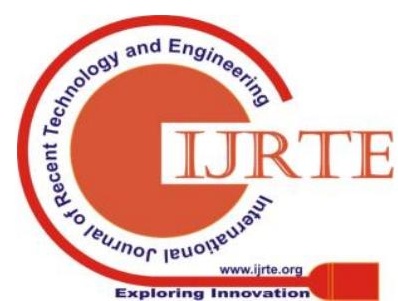


of Business and Management, 11(2), 69.

14. Emmerling, R. J. \& Goleman, D. (2003, October). Emotional intelligence: Issues and common misunderstandings. Issues and Recent Developments in Emotional Intelligence,1(1), Retrieved [date], from http://www.eiconsortium.org

15.https://www.forbes.com/sites/forbescoachescouncil/2018/03/2 2/how-and-why-to-develop-your-emotionalintelligence/\#6d58025a669b

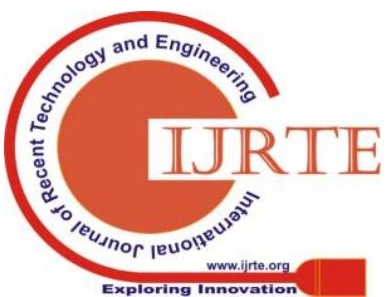

